\title{
Socioeconomic Inequalities in the Oral Health of People Aged 15-40 Years in Kurdistan, Iran in 2015: A Cross- sectional Study
}

\author{
Ghobad Moradi' ${ }^{1}$, Ardavan Moinafshar ${ }^{2}$, Hemen Adabi ${ }^{2}$, Mona Sharafi' ${ }^{2}$ Farideh Mostafavi' , Amjad Mohamadi Bolbanabad' \\ ${ }^{1}$ Social Determinants of Health Research Center, Kurdistan University of Medical Sciences, Sanandaj; ${ }^{2}$ Student Research Committee, Kurdistan \\ University of Medical Sciences, Sanandaj, Iran
}

Objectives: The aim of this study was to evaluate socioeconomic inequalities in the prevalence of dental caries among an urban population.

Methods: This study was conducted among 2000 people 15-40 years of age living in Kurdistan, Iran in 2015. Using a questionnaire, data were collected by 4 trained dental students. The dependent variable was the decayed, missing, and filled teeth (DMF) index. Using principal component analysis, the socioeconomic status (SES) of families was determined based on their household assets. Inequality was measured using the concentration index; in addition, the Oaxaca analytical method was used to determine the contribution of various determinants to the observed inequality.

Results: The concentration index for poor scores on the DMF index was -0.32 ( $95 \%$ confidence interval $[\mathrm{Cl}],-0.40$ to -0.36$)$; thus, poor DMF indices had a greater concentration in groups with a low SES $(p<0.001)$. Decomposition analysis showed that the mean prevalence of a poor DMF index was $43.7 \%(95 \% \mathrm{Cl}, 40.4$ to $46.9 \%)$ in the least privileged group and $14.4 \%(95 \% \mathrm{Cl}, 9.5$ to $9.2 \%)$ in the most privileged group. It was found that $85.8 \%$ of the gap observed between these groups was due to differences in sex, parents' education, and the district of residence. A poor DMF index was less prevalent among people with higher SES than among those with lower SES (odds ratio, $0.31 ; 95 \% \mathrm{Cl}, 0.19$ to 0.52 ).

Conclusions: An alarming degree of SES inequality in oral health status was found in the studied community. Hence, it is suggested that inequalities in oral health status be reduced via adopting appropriate policies such as the delivery of oral health services to poorer groups and covering such services in insurance programs.

Key words: Health equity, Social class, DMF index, Oral health, Iran

Received: March 2, 2017 Accepted: July 14, 2017

Corresponding author: Ghobad Moradi, MD, PhD

Pasdaran Ave., Sanandaj 66177-13446, Iran

Tel: +98-87-3313-1366, Fax: +98-87-3366-4651

E-mail: Moradi_gh@yahoo.com

This is an Open Access article distributed under the terms of the Creative Commons Attribution Non-Commercial License (http://creativecommons.org/licenses/bync/4.0/) which permits unrestricted non-commercial use, distribution, and reproduction in any medium, provided the original work is properly cited.

\section{INTRODUCTION}

Reducing inequalities in people's access to health care services is one of the main objectives of the health system in every country. Thus, policymakers are trying to find methods of reducing these inequalities [1]. However, most countries continue to face socioeconomic inequalities in access to health services $[2,3]$. 
Socioeconomic inequalities in health refer to differences in health indicators across various groups in a community in terms of social and economic characteristics such as education and income [4], which have a major impact on health indicators [5]. Health inequalities and socioeconomic inequalities in health manifest as differences in the incidence or prevalence of health problems among various populations and different socioeconomic groups [6].

Oral health is not exempted from this rule. The prevalence of oral diseases among different populations around the world is associated with their socioeconomic status (SES) [7-10]. Oral and dental care is of great importance because it imposes a significant financial burden on patients, their families, the health system, and the whole community. Therefore, to improve people's access to services, it is essential to identify factors affecting the utilization of oral and dental care services in every country $[11,12]$.

Various indicators are used to assess the utilization of oral and dental health services, including the decayed, missing, and filled teeth (DMF) index. The DMF index is the most important index of oral health status used worldwide in epidemiological studies [13]. This index can determine the number of teeth that need treatment for caries; it is also used to determine the number of teeth that have been lost because of decay [7]. Data obtained using this index can be utilized to assess the oral health of communities and to design relevant programs and policies. For example, the data obtained from the assessment of this index can be used as a measure to evaluate caries prevention programs, such as adding fluoride to the water and distributing syrup or liquid fluoride among students. The results of such studies might also pave the way for the delivery of oral health services and other prevention programs [14,15].

In Iran, the main health insurance program does not cover dentistry services, and the out-of-pocket payments are high. Some complementary health insurance programs cover dentistry services, but such insurance coverage is not readily available to the entire population [16]. According to the statistics published by the Iranian Medical Council [17], of a total of about 20000 dentists, $80 \%$ are working in the private sector and $20 \%$ in the public sector.

The prevalence of dental lesions in Iran is high. Approximately $50 \%$ of children aged 12 years have tooth caries [18]. Given the oral health conditions in Iran, there is a need for immediate interventions and up-to-date strategies to promote oral health. Currently, due to the lack of health insurance cov- erage and expensive costs, large groups of people are suffering from dental problems [19].

Due to the lack of insurance coverage, the high cost of services, and people's limited access to oral health services, it is very valuable to study inequalities in oral health status indicators. To the best of our knowledge, no study has yet investigated the distribution of this index among different socioeconomic groups in Iran and even in countries within the Eastern Mediterranean Regional Office (EMRO) region. Considering the above facts, the aim of this study was to evaluate socioeconomic inequalities in the oral health status among an Iranian urban population based on the DMF index.

\section{METHODS}

\section{Study Design and Participants}

This cross-sectional study was conducted in 2015 in Sanandaj, the capital city of Kurdistan Province in the western part of Iran. The study population included people 15-40 years of age who were living in Sanandaj, and the sample size was 2000 persons. Using the cluster sampling method, 10 persons who were within the desired age range were selected from each cluster and were enrolled into the study. Cluster heads were selected on the basis of the geo-codes of Sanandaj; the required data were obtained from the Post Office. The required data were collected via completing a questionnaire, examinations, and visiting households. The data was collected by 4 trained interviewers who were dental students; they were trained in how to examine and complete the questionnaire. Before the field survey, 4 trained examiners were calibrated in conducting oral examinations among 25 persons from the research community, in order to reduce inter-examiner inconsistency. The mean inter-examiner consistency in recording dental caries was $92 \%$. They visited the subjects' home and completed the questionnaire via direct observation and examination using a number 4 mirror and a Medisporex catheter. During the examination, the respondents and researchers sat near the window, in order to ensure the maximum amount of natural light.

\section{Outcome Measures}

In this study, the DMF index was the outcome measure used to determine the number of DMF. In order to analyze the data, first we determined the DMF index and then converted it to a binary index, corresponding to the categories of favorable and unfavorable oral health status. To determine the DMF index 
and to dichotomize it into favorable and unfavorable status, we took the following steps. Consensus was reached in an expert panel including 2 dentists, 2 epidemiologists, and a health economist. We decided to give more weight to missing teeth $(M)$, because of the financial problems associated with teeth recovery, than to filled teeth $(F)$, which can be a sign of financial accessibility. First, the number of $\mathrm{M}$ for each individual was multiplied by 2 so that it received a greater coefficient. Then, we specified the number of decayed teeth (D) and multiplied it by 1 . Next, the number of $F$ was counted and was multiplied by 0.5 so that it received a lower weight. Based on these calculations, a score was obtained for each person. Based on these calculations, a score was obtained for each person. Dental caries is a lifetime disease, with highest-priority risk group between 11 and 14 years of age [20]. Moreover, the World Health Organization considers a DMF index of 6.5 to be very high in children, but low at 35-44 years old [21]. Therefore, we assigned a greater weight to younger people with an equivalent amount of decay. Thus, the scores obtained for people aged less than 25 years old were multiplied by 1.5 . In people aged over 25 years, their scores were multiplied by 1 . We then specified a cut-off point to define favorable and unfavorable status. The cut-off point was set at the third quartile or $75 \%$. People whose score was above the third quartile were considered to have a poor oral health status, while those whose score was less than $75 \%$ were considered to have a favorable oral health status.

\section{Socioeconomic Status Indicators}

To determine SES, we used the method proposed by O'Donnell et al. [22] in 2008. A questionnaire was used to collect data on a number of home assets, including the following: a separate bathroom, a separate kitchen, vacuum cleaners, computers, separate refrigerators, a washing machine, color TV, LCD TV, mobile phones, a dishwasher, a microwave oven, Internet access, a personal car, a landline phone, a personal home, the number of rooms, heating appliances, an oven, a microwave, and furniture. On the basis of each asset, the asset index for every person was calculated using principal component analysis. Based on this indicator, the study population was divided into 5 quintiles: very poor, poor, mediocre, rich, and very rich. Among these groups, the quintiles of the very poor and very rich were entered into the Oaxaca model. Some studies have also used assets to determine SES in the Iranian population $[23,24]$.

\section{Statistical Analysis}

The concentration curve and concentration index were used to measure inequality. If all the people in various socioeconomic groups have the same health status, the concentration index will be zero and the concentration curve will be tangent to the line of equality. If a given variable is concentrated in low SES groups, the concentration index will be negative and above the line of equality, and if it is concentrated in high SES groups, the concentration index will be positive and below the line of equality [25].

After measuring inequalities, the Oaxaca decomposition method was used to determine the share of each socioeconomic determinant and the size of their effects on inequality. Using the Oaxaca method, it is possible to determine the changes in the mean $y$ caused by changes in the inequality in $\chi$. The general Oaxaca formula (1) is as follows:

$$
\begin{aligned}
y^{\text {non-poor }-y^{\text {poor }}} & =\Delta \chi \beta^{\text {poor }}+\Delta \beta \chi^{\text {poor }}+\Delta \chi \Delta \beta \\
& =E+C+C E-
\end{aligned}
$$

The Oaxaca method breaks down the mean difference in the outcome variables into 2 components. $E$ (explained) is the difference in the mean $\chi$ value or in the determinants, $C$ is the difference in the mean coefficients or the unexplained items, and $C E$ is the interaction between the differences in $\chi$ and the coefficients [18]. In order to calculate the share of each of the subcomponents relative to the total difference, the following Oaxaca decomposition formula (2) was used:

$$
\begin{aligned}
y^{\text {non-poor }}-y^{\text {poor }}= & \left(\beta 0^{\text {non-poor }}-\beta 0^{\text {poor }}\right)+\left(\beta 1^{\text {non-poor }} \chi 1^{\text {non-poor }}\right. \\
\left.-\beta 1^{\text {poor }} \chi 1^{\text {poor }}\right)+ & \left(\beta 2^{\text {non-poor }} \chi 2^{\text {non-poor- }} \beta 2^{\text {poor }} \chi 2^{\text {poor }}\right) \\
= & G_{0}+G_{1}+G_{2}-
\end{aligned}
$$

In this formula, $y$ is the outcome variable (i.e., poor DMF), $\mathrm{G}_{0}$ is the difference in intercepts; $G_{1}$ is the difference between $\chi 1$ and $\beta 1$; and $G_{2}$ is the difference between $\chi 2$ and $\beta 2$. In order to perform decomposition, first we used logistic regression to assess the relationship between oral health status and different determinants, including age, sex, parents' education, parents' age, and economic groups. The variables that were significantly associated with the outcome were entered into Oaxaca model. In all the models, $p=0.05$ was set as the significance level. The data were analyzed using Stata version 13 (StataCorp., College Station, TX, USA). 
Table 1. Descriptive characteristics and prevalence of a poor DMF index

\begin{tabular}{|c|c|c|c|c|c|}
\hline & n (\%) & Poor DMF (\%) & OR (95\% CI) & Adjusted OR (95\% CI) & $p$-value \\
\hline \multicolumn{6}{|l|}{ Sex } \\
\hline Male & 1039 (51.8) & $284(27.3)$ & 1.00 (reference) & 1.00 (reference) & \\
\hline Female & $961(48.1)$ & $236(24.5)$ & $0.86(0.70,1.05)$ & $0.71(0.56,0.91)$ & 0.007 \\
\hline \multicolumn{6}{|l|}{ Maternal education } \\
\hline Uneducated or elementary & $294(14.8)$ & $143(48.6)$ & 1.00 (reference) & 1.00 (reference) & \\
\hline Junior or senior high school & $473(23.8)$ & $194(41.0)$ & $0.73(0.54,0.98)$ & $1.08(0.70,1.67)$ & 0.69 \\
\hline Academic degree & $1226(61.5)$ & $181(14.8)$ & $0.18(0.13,0.24)$ & $0.60(0.37,0.96)$ & 0.03 \\
\hline \multicolumn{6}{|l|}{ Paternal education } \\
\hline Uneducated or elementary & $189(9.5)$ & $87(46.0)$ & 1.00 (reference) & 1.00 (reference) & \\
\hline Junior or senior high school & $413(20.8)$ & $198(47.0)$ & $1.07(0.76,1.52)$ & $1.47(0.93,2.34)$ & 0.09 \\
\hline Academic degree & $1398(69.8)$ & $235(16.8)$ & $0.23(0.17,0.32)$ & $0.73(0.43,1.24)$ & 0.25 \\
\hline \multicolumn{6}{|l|}{ Education } \\
\hline Uneducated or elementary & $24(1.2)$ & $9(37.5)$ & 1.00 (reference) & 1.00 (reference) & \\
\hline Junior or senior high school & $461(22.9)$ & $189(41.0)$ & $1.15(0.49,2.70)$ & $1.51(0.60,3.79)$ & 0.37 \\
\hline Academic degree & $1515(75.9)$ & $322(21.3)$ & $0.44(0.19,1.03)$ & $1.10(0.44,2.74)$ & 0.83 \\
\hline \multicolumn{6}{|l|}{ SES quintile } \\
\hline Poorest & $895(44.8)$ & $391(43.7)$ & 1.00 (reference) & 1.00 (reference) & \\
\hline Second & $370(18.5)$ & $54(14.6)$ & $0.22(0.16,0.30)$ & $0.34(0.24,0.49)$ & 0.001 \\
\hline Middle & $282(14.2)$ & $23(8.2)$ & $0.11(0.07,0.17)$ & $0.23(0.14,0.38)$ & 0.001 \\
\hline Fourth & $241(12.0)$ & $21(8.7)$ & $0.12(0.07,0.19)$ & $0.24(0.14,0.41)$ & 0.001 \\
\hline Richest & $209(10.5)$ & $30(14.4)$ & $0.21(0.14,0.32)$ & $0.31(0.19,0.52)$ & 0.001 \\
\hline \multicolumn{6}{|l|}{ Age (y) } \\
\hline $15-24$ & 744 (33.2) & $251(33.7)$ & 1.00 (reference) & 1.00 (reference) & \\
\hline $25-34$ & 735 (36.7) & $96(13.0)$ & $0.29(0.22,0.38)$ & $0.20(0.13,0.29)$ & 0.001 \\
\hline $35-40$ & $521(26.0)$ & $173(33.2)$ & $0.97(0.77,1.23)$ & $0.85(0.55,1.32)$ & 0.48 \\
\hline \multicolumn{6}{|l|}{ Marital status } \\
\hline Single & 1012 (50.7) & $263(26.0)$ & 1.00 (reference) & 1.00 (reference) & \\
\hline Married & $911(45.5)$ & $226(24.8)$ & $0.93(0.76,1.15)$ & $1.06(0.72,1.56)$ & 0.73 \\
\hline Others & $77(3.9)$ & $31(40.3)$ & $1.91(1.19,3.09)$ & $1.26(0.66,2.43)$ & 0.47 \\
\hline \multicolumn{6}{|l|}{ District of residence ${ }^{1}$} \\
\hline 1 & $436(21.9)$ & $216(49.5)$ & 1.00 (reference) & 1.00 (reference) & \\
\hline 2 & $740(37.0)$ & $193(26.0)$ & $0.35(0.28,0.46)$ & $0.57(0.42,0.77)$ & 0.001 \\
\hline 3 (high SES) & $824(41.0)$ & $111(13.47)$ & $0.15(0.12,0.20)$ & $0.42(0.30,0.59)$ & 0.001 \\
\hline \multicolumn{6}{|l|}{ Insurance status } \\
\hline No & $407(20.5)$ & $172(42.3)$ & 1.00 (reference) & 1.00 (reference) & \\
\hline Yes & 1589 (79.4) & $345(21.7)$ & $0.37(0.30,0.47)$ & $0.98(0.73,1.32)$ & 0.90 \\
\hline
\end{tabular}

DMF, decayed, missing, filled teeth; OR, odds ratio; $\mathrm{Cl}$, confidence interval; SES, socioeconomic status.

${ }^{1}$ Categorized by SES.

\section{RESULTS}

Data were collected from 2000 people. Table 1 shows the main characteristics of the participants in the study. A majority of the participants (51.8\%) were male. Of the females, $61.5 \%$ were educated and had an academic degree. In addition, $50.7 \%$ of the study participants were single. Most of the partic- ipants were in the first and second quintiles (44.8 and 18.5\%, respectively). Moreover, $26.0 \%$ ( $95 \% \mathrm{Cl}, 24.0$ to $27.9 \%)$ of the participants had a poor DMF index, which was more prevalent among people in the lowest socioeconomic quintile (43.7\%).

Based on the results shown in Table 1, a poor DMF index was less prevalent among people with high SES than among those with lower SES (odds ratio [OR], $0.31 ; 95 \% \mathrm{Cl}, 0.19$ to 0.52 ). 


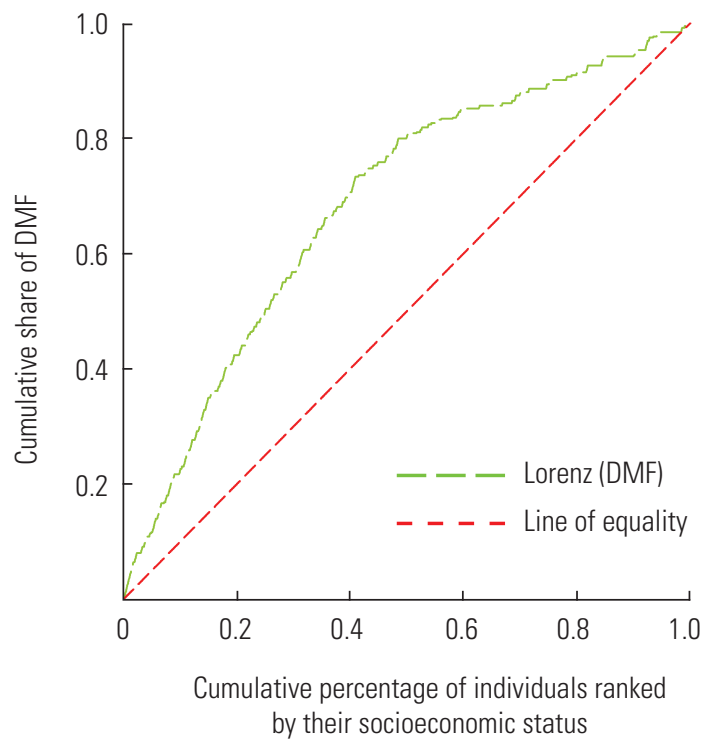

Figure 1. Concentration curve of the decayed, missing, and filled teeth (DMF) index.

There was an inverse association between the SES status of the district of residence and the prevalence of a poor DMF in$\operatorname{dex}(\mathrm{OR}, 0.42 ; 95 \% \mathrm{Cl}, 0.30$ to 0.59$)$, meaning that a poor DMF index was less prevalent among people living in areas with high SES. Moreover, a poor DMF index was less prevalent among females than males ( $\mathrm{OR}, 0.71 ; 95 \% \mathrm{Cl}, 0.56$ to 0.91$)$. The maternal educational level was a protective factor against a poor DMF index, as people whose mothers had a history of academic education were at a lower risk for poor DMF (OR, 0.60; $95 \% \mathrm{Cl}, 0.37$ to 0.96$)$. In this study, a poor DMF index had no association with individuals' education, marital status, paternal education, or insurance status.

The concentration index was used to determine inequality. The concentration index for the DMF index was $-0.36(95 \% \mathrm{Cl}$, -0.40 to -0.32 ), which indicated a higher concentration of poor DMF index scores in those with low SES $(p<0.001)$. The concentration curve for the DMF index was above the line of equality, indicating a higher prevalence of a poor DMF index among people with low SES (Figure 1).

After determining the level of inequality, the Oaxaca decomposition method was used to calculate the share of each of the determinants. The independent variables in the logistic regression model were entered into the Oaxaca model. The results of the decomposition analysis showed that the mean prevalence of poor oral health was $43.65 \%(95 \% \mathrm{Cl}, 40.39$ to $46.92 \%)$ among the least privileged group and $14.35 \%$ (95\%
$\mathrm{Cl}, 9.54$ to $19.16 \%$ ) among the most privileged group, meaning that the difference between them was 29.30 percentage points. Moreover, $85.87 \%$ of the gap observed between these groups was due to differences in the studied variables, including sex, parents' education, and district of residence. Maternal education (55.04\%) and paternal education (44.95\%) made the largest contribution to this discrepancy. The rest of the socioeconomic gap between the groups (i.e., $45.73 \%$ of the total gap) was unexplained and was due to differences in the coefficients or other factors that were not included in the study. Moreover, $31.60 \%$ of the gap could be attributed to the interaction between these two components (Table 2).

\section{DISCUSSION}

Based on the findings of this study, a poor DMF index was more prevalent among people with low SES, and there were significant differences across socioeconomic groups in terms of this indicator. Many reports have been published on socioeconomic inequalities in oral health status all around the world; for instance, socioeconomic inequality in oral health status has been reported to be an important factor in Finland. Although many interventions have been designed and implemented, inequality has been reduced, but not eliminated. Based on the results of continuous monitoring, it has been recommended to design continuous interventions to improve the status of oral health in low socioeconomic groups [26,27]. In Canada, inequalities in oral health have been reported. Accordingly, Canada has adopted policies to reduce inequalities in oral health services and has designed and implemented some interventions [28]. Likewise, in Australia, SES was found to have an impact on children's oral health status [29]. In a study in Thailand [30], large inequalities in oral health status were reported. That study recommending integrating oral health services with primary health care services to reduce inequality in Thailand. A study in Brazil used the Gini index to report inequality in oral health status. The study showed that as the Gini coefficient increased, oral health inequality increased as well. However, improving SES has a huge impact on improving oral health indicators [31]. The poor DMF in lower socioeconomic groups may be due to the fact that the major forms of health insurance do not cover dental services, meaning that patients have high out-of-pocket payments; in addition, complementary health insurance is not available to lower socioeconomic groups. 
Table 2. Decomposition of the difference in the DMF index between the richest and poorest groups

\begin{tabular}{|c|c|c|c|c|}
\hline & \multirow{2}{*}{ Prediction (\%) } & \multicolumn{2}{|c|}{$95 \% \mathrm{Cl}$} & \multirow{2}{*}{$p$-value } \\
\hline & & Lower & Upper & \\
\hline \multicolumn{5}{|l|}{ DMF group } \\
\hline Poorest & 43.65 & 40.39 & 46.92 & 0.001 \\
\hline Richest & 14.35 & 9.54 & 19.16 & 0.001 \\
\hline Difference (total gap) & 29.30 & 23.48 & 35.12 & 0.001 \\
\hline \multicolumn{5}{|l|}{ Due to coefficient (explained) } \\
\hline Sex & -0.69 & -1.82 & 0.42 & 0.22 \\
\hline Age & 0.54 & -0.47 & 1.15 & 0.29 \\
\hline District of residence & 0.15 & -7.22 & 7.52 & 0.96 \\
\hline Paternal education & 11.31 & 3.70 & 18.92 & 0.004 \\
\hline Maternal education & 13.85 & 5.87 & 21.84 & 0.001 \\
\hline Subtotal of gap (explained part) & 25.16 & 14.89 & 35.44 & 0.001 \\
\hline \multicolumn{5}{|l|}{ Due to coefficient (unexplained) } \\
\hline Sex & 10.30 & -5.40 & 26.01 & 0.19 \\
\hline Age & 7.81 & -5.88 & 21.52 & 0.26 \\
\hline District of residence & 14.82 & 3.11 & 26.53 & 0.01 \\
\hline Paternal education & 43.12 & 2.72 & 83.52 & 0.03 \\
\hline Maternal education & 44.30 & 9.72 & 78.88 & 0.01 \\
\hline Subtotal of gap (unexplained part) & 13.40 & 6.27 & 20.52 & 0.001 \\
\hline \multicolumn{5}{|l|}{ Due to interaction } \\
\hline Sex & 0.81 & -0.54 & 2.17 & 0.23 \\
\hline Age & -0.67 & -1.94 & 0.59 & 0.30 \\
\hline District of residence & 10.71 & 2.20 & 19.22 & 0.01 \\
\hline Paternal education & -8.83 & -17.18 & -0.48 & 0.03 \\
\hline Maternal education & -11.28 & -20.19 & -2.38 & 0.01 \\
\hline Total (interaction part) & -9.26 & -20.29 & 1.76 & 0.10 \\
\hline
\end{tabular}

DMF, decayed, missing, filled teeth; $\mathrm{Cl}$, confidence interval.

The results of our study showed an inverse relationship between the SES of the district of residence and the prevalence of a poor DMF index. People with low SES had a poor DMF index, which can be primarily attributed to the lack of financial access to dental care services. A study in Norway and Sweden showed socioeconomic inequalities in oral health status. The study also suggested that oral health was linked to SES and an individual's district of residence during childhood and adolescence. The study also indicated that oral health status in middle-aged people was associated with marital status [32]. Other studies have also reported an association between place of residence and oral health status [33,34].

In this study, a poor DMF index was less prevalent among girls than boys. According to a previous study, oral health status was poorer in girls than in boys, but that finding is not consistent with the results of our study [35]. Nonetheless, studies similar to ours reported that young females had a bet- ter oral health status [36]. The poorer oral health status of young and adult males may be attributed to high-risk behaviors, such as smoking, in males.

The results of our study showed that parental education, especially maternal education, played an important role in oral health status. Higher levels of maternal education and awareness reduced oral health inequalities. A study in Mexico showed that people with lower educational attainment were at a greater risk of poor oral health status [37]. This might be due to the fact that living conditions during childhood have a significant impact on oral health status in older ages. Even older people with a high SES may have a poor oral health status because of their poor oral health conditions during their early childhood.

As one of the limitations of this study, because of financial and logistical constraints, this study was conducted only in an urban environment. In addition, because of the same con- 
straints, we were not able to cover all age groups, which is another limitation of this study.

This study is the first study in Iran and the EMRO region to evaluate socioeconomic inequalities in oral health using inequality metrics. We assessed oral health status based on the DMF index in a sample of the urban population aged 15-40 years, and the results indicated the presence of a poor DMF index in the studied population. The extent of socioeconomic inequality was high, impressive, and alarming. Lower socioeconomic groups had a poor oral health status. Hence, it is recommended to adopt macro-level policies to reduce inequality. In order to ensure justice in oral health indicators, it is necessary to include relevant objectives in the general oral health policies in Iran and other countries. Oral health status may improve through providing oral health services to poorer groups, training parents, and increasing people's education levels. The inclusion of oral health services in insurance plans and primary health care services can play an important role in reducing inequality. It is also recommended to conduct more comprehensive studies among other age groups and to continually monitor the status of health equity.

\section{ACKNOWLEDGEMENTS}

This research project was approved and funded by the Social Determinants of Health Research Center, Kurdistan University of Medical Sciences.

\section{CONFLICT OF INTEREST}

The authors have no conflicts of interest associated with the material presented in this paper.

\section{ORCID}

Ghobad Moradi https://orcid.org/0000-0003-2612-6528

Ardavan Moinafshar https://orcid.org/0000-0001-5093-1223

Hemen Adabi http://orcid.org/0000-0001-9270-7676

Mona Sharafi https://orcid.org/0000-0003-1916-9722

Farideh Mostafavi https://orcid.org/0000-0002-1611-3806

Amjad Mohamadi Bolbanabad http://orcid.org/0000-00015567-641X

\section{REFERENCES}

1. Roberts M, Hsiao W, Berman P, Reich M. Getting health reform right: a guide to improving performance and equity. New York: Oxford University Press; 2008, p. 352.

2. Vandenheede H, Vikhireva O, Pikhart H, Kubinova R, Malyutina $S$, Pajak $A$, et al. Socioeconomic inequalities in all-cause mortality in the Czech Republic, Russia, Poland and Lithuania in the 2000s: findings from the HAPIEE Study. J Epidemiol Community Health 2014;68(4):297-303.

3. Hu Y, van Lenthe FJ, Borsboom GJ, Looman CW, Bopp M, Burström $B$, et al. Trends in socioeconomic inequalities in self-assessed health in 17 European countries between 1990 and 2010. J Epidemiol Community Health 2016;70(7):644-652.

4. Braveman P. Health disparities and health equity: concepts and measurement. Annu Rev Public Health 2006;27:167-194.

5. Culyer AJ, Wagstaff A. Equity and equality in health and health care. J Health Econ 1993;12(4):431-457.

6. Braveman $P$, Gruskin S. Defining equity in health. J Epidemiol Community Health 2003;57(4):254-258.

7. Roland $\mathrm{E}$, Gueguen $\mathrm{G}$, Longis MJ, Boiselle J. Validation of the reproducibility of the DMF Index used in bucco-dental epidemiology and evaluation of its 2 clinical forms. World Health Stat Q 1994;47(2):44-61 (French).

8. Tsakos G, Demakakos P, Breeze E, Watt RG. Social gradients in oral health in older adults: findings from the English longitudinal survey of aging. Am J Public Health 2011;101(10):18921899.

9. Elani HW, Harper S, Allison PJ, Bedos C, Kaufman JS. Socioeconomic inequalities and oral health in Canada and the United States. J Dent Res 2012;91(9):865-870.

10. Turrell G, Sanders AE, Slade GD, Spencer AJ, Marcenes W. The independent contribution of neighborhood disadvantage and individual-level socioeconomic position to self-reported oral health: a multilevel analysis. Community Dent Oral Epidemiol 2007;35(3):195-206.

11. Cohen-Carneiro F, Souza-Santos R, Rebelo MA. Quality of life related to oral health: contribution from social factors. Cien Saude Colet 2011;16 Suppl 1:1007-1015.

12. Marin $\mathrm{GH}$, Urdampilleta $\mathrm{P}$, Zurriaga O. Determinants of dental care utilization by the adult population in Buenos Aires. Med Oral Patol Oral Cir Bucal 2010;15(2):e316-e321.

13. Broadbent JM, Thomson WM. For debate: problems with the DMF index pertinent to dental caries data analysis. Community Dent Oral Epidemiol 2005;33(6):400-409. 
14. Marthaler TM. Changes in dental caries 1953-2003. Caries Res 2004;38(3):173-181.

15. Nadanovsky P, Sheiham A. Relative contribution of dental services to the changes in caries levels of 12-year-old children in 18 industrialized countries in the 1970 s and early 1980s. Community Dent Oral Epidemiol 1995;23(6):331-339.

16. Homaie Rad E, Kavosi Z, Arefnezhad M. Economic inequalities in dental care utilizations in Iran: evidence from an urban region. Med J Islam Repub Iran 2016;30:383.

17. Kiadaliri AA, Hosseinpour R, Haghparast-Bidgoli $H$, Gerdtham UG. Pure and social disparities in distribution of dentists: a cross-sectional province-based study in Iran. Int J Environ Res Public Health 2013;10(5):1882-1894.

18. Pakshir HR. Oral health in Iran. Int Dent J 2004;54(6 Suppl 1): 367-372.

19. Asgari F, Majidi A, Koohpayehzadeh J, Etemad K, Rafei A. Oral hygiene status in a general population of Iran, 2011: a key lifestyle marker in relation to common risk factors of noncommunicable diseases. Int J Health Policy Manag 2015;4(6): 343-352.

20. ur Rehman MM, Mahmood N, ur Rehman B. The relationship of caries with oral hygiene status and extra-oral risk factors. J Ayub Med Coll Abbottabad 2008;20(1):103-108.

21. World Health Organization. Oral health surveys: basic methods. 5th ed. Geneva: World Health Organization; 2013, p. 74.

22. O'Donnell O, Van Doorslaer E, Wagstaff A, Lindelow M. Analyzing health equity using household survey data a guide to techniques and their implementation. Washington, DC: World Bank; 2008, p. 71, 150.

23. Moradi G, Mohammad K, Majdzadeh R, Ardakani HM, Naieni $\mathrm{KH}$. Socioeconomic inequality of non-communicable risk factors among people living in Kurdistan Province, Islamic Republic of Iran. Int J Prev Med 2013;4(6):671-683.

24. Moradi G, Majdzadeh R, Mohammad K, Malekafzali H, Jafari S, Holakouie-Naieni K. Is the status of diabetes socioeconomic inequality changing in Kurdistan Province, west of Iran? A comparison of two surveys. Med J Islam Repub Iran 2016;30: 375.

25. Bammann K, Gwozdz W, Lanfer A, Barba G, De Henauw S, Eiben $\mathrm{G}$, et al. Socioeconomic factors and childhood overweight in Europe: results from the multi-centre IDEFICS study. Pediatr Obes 2013;8(1):1-12.

26. Raittio E, Lahti S, Kiiskinen U, Helminen S, Aromaa A, Suominen AL. Inequality in oral health-related quality of life before and after a major subsidization reform. Eur J Oral Sci 2015;123 (4):267-275.

27. Raittio E, Aromaa A, Kiiskinen U, Helminen S, Suominen AL. Income-related inequality in perceived oral health among adult Finns before and after a major dental subsidization reform. Acta Odontol Scand 2016;74(5):348-354.

28. Moeller J, Quiñonez C. The association between income inequality and oral health in Canada: a cross-sectional study. Int J Health Serv 2016;46(4):790-809.

29. Do LG, Scott JA, Thomson WM, Stamm JW, Rugg-Gunn AJ, Levy SM, et al. Common risk factor approach to address socioeconomic inequality in the oral health of preschool children: a prospective cohort study. BMC Public Health 2014;14:429.

30. Somkotra T. Inequality in oral health-care utilisation exists among older Thais despite a universal coverage policy. Australas J Ageing 2013;32(2):110-114.

31. Celeste RK, Nadanovsky P. How much of the income inequality effect can be explained by public policy? Evidence from oral health in Brazil. Health Policy 2010;97(2-3):250-258.

32. Gülcan F, Ekbäck G, Ordell S, Lie SA, Åstrøm AN. Inequality in oral health related to early and later life social conditions: a study of elderly in Norway and Sweden. BMC Oral Health 2015;15:20.

33. Jamieson LM, Thomson WM. Adult oral health inequalities described using area-based and household-based socioeconomic status measures. J Public Health Dent 2006;66(2):104109.

34. Ha DH, Do LG, Luzzi L, Mejia GC, Jamieson L. Changes in arealevel socioeconomic status and oral health of indigenous Australian children. J Health Care Poor Underserved 2016;27(1 Suppl):110-124.

35. Inglehart MR, Patel MH, Widmalm SE, Briskie DM. Self-reported temporomandibular joint disorder symptoms, oral health, and quality of life of children in kindergarten through grade 5 : do sex, race, and socioeconomic background matter? J Am Dent Assoc 2016;147(2):131-141.

36. Furuta M, Ekuni D, Irie K, Azuma T, Tomofuji T, Ogura T, et al. Sex differences in gingivitis relate to interaction of oral health behaviors in young people. J Periodontol 2011;82(4):558-565.

37. Hernández-Palacios RD, Ramírez-Amador V, Jarillo-Soto EC, Irigoyen-Camacho ME, Mendoza-Núñez VM. Relationship between gender, income and education and self-perceived oral health among elderly Mexicans. An exploratory study. Cien Saude Colet 2015;20(4):997-1004. 